\title{
PENGARUH CORPORATE GOVERNANCE TERHADAP FINANCIAL RESTATEMENT PADA PERUSAHAAN DI INDONESIA
}

\author{
Desy Ismah Anggraini \\ dessy.xi.ia@gmail.com \\ Universitas Airlangga \\ Wiwiek Dianawati \\ wiwiek.dianawati@yahoo.com \\ Universitas Airlangga
}

\begin{abstract}
This study examines the influence of the number of boards of directors, proportion of independent commissioners and the frequency of audit committee meetings on financial restatement. The study used samples of listed companies ion Indonesia Stock Exchange (IDX) in all industries with excluding the financial industry, and the study period in 2012 to 2016. Result show that the number of board of directors and proportion of independent commissioners in company has a negative relationship to the restatement, but is not significant. The frequency of audit committee meetings has a positive and significant relationship, but is not in accordance with the research hypothesis.
\end{abstract}

Keywords : restatement, boards of directors, independent commissioners, audit committee meetings

\section{PENDAHULUAN}

Sumber informasi penting yang dapat menyampaikan kinerja perusahaan dan dibutuhkan oleh investor adalah laporan keuangan. Pentingnya laporan keuangan membuat laporan tersebut harus berkualitas dan akurat. Apabila dalam laporan keuangan tersebut terdapat kesalahan dan ditemukan oleh regulator, maka perusahaan harus menyajikan kembali laporan keuangannya (financial restatement selanjutnya disebut restatement). Restatement dapat meningkatkan integritas dari informasi keuangan, namun di sisi lain dengan adanya kejadian financial restatement juga memberikan peluang manajer untuk memanipulasi data akuntansi sehingga manajer dapat menggunakan laporan keuangan dan kompleksitas dari restatement untuk menghilangkan jejak manajemen labanya (Cai dkk., 2014).

Penyebab terjadinya restatement bervariasi, terutama ada indikasi terjadinya kecurangan (fraud) sehingga menimbulkan kekhawatiran mengenai kemampuan corporate governance dan fungsinya dalam mengawasi dan mengungkapkan laporan keuangan (GAO, 2002). Penelitian yang dilakukan oleh Abbott dkk. (2004); Agrawal dkk. (2005); Veronica dkk. (2005); Lin dkk. (2006), Yuristisia dkk. (2008); Yuristisia 
dkk. (2008); Nahar Abdullah dkk. (2010); Zhizhong dkk. (2011); Rani dkk. (2011); dan Pertiwi (2017) juga mengasumsikan bahwa financial restatement dapat dicegah atau dikendalikan dengan fungsi internal corporate governance yang kuat. Berdasarkan literatur penelitian tersebut, peneliti menarik kesimpulan bahwa variabel utama yang dapat mempengaruhi restatement antara lain ukuran dewan direksi, proporsi komisaris independen, frekuensi rapat komite audit, dan independensi komite audit.

Terjadinya financial restatement yang diakibatkan karena adanya interaksi dari beberapa faktor, diantaranya adalah struktur corporate governance yaitu dewan direksi. Hubungan antara dewan direksi dan restatement diteliti oleh Hasnan, Marzuki, dkk. (2017) dan Hasnan dan Marzuki (2017) menunjukkan bahwa adanya hubungan negatif dan signifikan antara ukuran dewan dengan financial restatement yang menunjukkan bahwa jumlah dapat memberikan sumberdaya tambahan pada pengetahuan dan pengalaman bisnis untuk memperbaiki kualitas dari pengawasan manajerial. Sebaliknya, Yuristisia dkk. (2008) menunjukkan bahwa adanya hubungan positif antara ukuran dewan direksi dengan accounting restatement. Hal ini berarti bahwa adanya hubungan yang positif antara ukuran dewan direksi degan kinerja perusahaan. Namun ada beberapa penelitian yang tidak signifikan terhadap ukuran dewan direksi, diantaranya Veronica dkk. (2005), Ma dkk. (2015). Hasil penelitian Ma dkk. (2015) dan Cai dkk. (2014) memunjukkan bahwa ukuran dewan direksi memiliki skala atau kurva yang saling berhubungan. Agrawal dkk. (2005) memprediksi bahwa jumlah dewan direksi yang lebih banyak lebih cenderung untuk memasukkan berbagai keahlian termasuk keahlian keuangan, namun hasil penelotian tidak signifikan.

Kehadiran komisaris independen yang tidak memiliki hubungan dengan pihak manajemen perusahaan diharapkan mampu memberikan pendapat secara objektif dan dapat memantau manajer perusahaan dengan lebih efektif sehingga transparansi dalam kinerja perusahaan dapat tercapai (Nahar Abdullah dkk., 2010; Zhizhong dkk., 2011). Hubungan antara proporsi komisaris independen dengan restatement telah diteliti oleh Zhizhong dkk. (2011), Veronica dkk. (2005), dan Beasley (1996) memiliki pendapat yang sama yaitu proporsi komisaris independen memiliki hubungan negatif terhadap restatement. Yuristisia dkk. (2008) memiliki pendapat lain tentang proporsi komisaris independen, yaitu proporsi komisaris independen berpengaruh positif terhadap accounting restatement pada perusahaan manufaktur. Sedangkan Nahar Abdullah dkk. (2010), Hasnan, Marzuki, dkk. (2017), Hasnan dan Marzuki (2017), Ma dkk. (2015) dan Cai dkk. (2014) mengukur proporsi komisaris independen yang memiliki hubungan negatif dengan restatement, namun hasil tidak menunjukkan adanya bukti hubungan negatif.

Rapat komite audit merupakan suatu indikator keaktifan komite audit dalam perusahaan, karena dengan adanya komite audit yang aktif diharapkan akan mampu mengurangi perilaku manajemen laba (earnings management) (Rani dkk., 2011). Selanjutnya Pertiwi (2017), Rani dkk. (2011), dan Lin dkk. (2006) memprediksi bahwa ada hubungan negatif antara frekuensi rapat yang dilakukan komite audit terhadap 
terjadinya earnings restatement. Namun, bukti menyatakan bahwa frekuensi rapat komite audit tidak memiliki hubungan dengan terjadinya earning restatement, hal ini disebabkan karena pembentukan komite audit adalah mandatori dan frekuensi rapat pertahun hanya untuk memenuhi peraturan.

Fenomena yang terjadi di Indonesia sejak tahun 2012 sampai tahun 2016 keterjadian restatement semakin berkurang dan memiliki presentase yang cukup rendah dari pada perusahaan yang tidak melakukan restatement yaitu tahun 2012 (2,67\%), 2013 (2,34\%), 2014 (2,02\%), 2015 (1,17\%), dan 2016 (2,06\%). Perusahaan yang melakukan restatement rata-rata disebabkan oleh kesalahan pencatatan, pajak tangguhan, penghentian operasi perusahaan, dan penurunan nilai aset.

Penelitian ini menggunakan data sekunder yang diambil dari laporan keuangan perusahaan yang terdaftar di Bursa Efek Indonesia (BEI) pada tahun 2012 sampai 2016. Pemilihan periode ini bertujuan untuk memberikan informasi terbaru terkait hubungan antara corporate governance terhadap restatement. Perusahaan sampel yang dipilih adalah seluruh perusahaan yang terdaftar di BEI dengan mengeluarkan industri keuangan, hal ini dilakukan agar tidak terjadi bias dalam penelitian. Selain itu, sampel penelitian yang digunakan sesuai dengan kriteria financial restatement GAO (2002).

Penelitian ini bertujuan untuk mengetahui pengaruh dari ukuran dewan direksi, proporsi komisaris independen, dan frekuensi rapat komite audit terhadap terjadinya restatement. Peneliti tertarik mengambil tema tersebut dikarenakan adanya ketidak konsistenan hasil pada beberapa penelitian terdahulu, selain itu masih relatif sedikit penelitian di Indonesia yang membahas restatement. Penelitian ini diharapkan dapat memberikan informasi tambahan kepada peneliti berikutnya sehingga dapat mengembangkan lagi penelitian ini. Peneliti juga berharap agar penelitian ini dapat menjadi referensi tambahan untuk investor dalam mempertimbangkan keputusan investasinya.

\section{TINJAUAN PUSTAKA DAN PERUMUSAN HIPOTESIS}

\section{Teori Agensi}

Teori Agensi menjelaskan pemisahan kepemilikan dari kontrol antara prinsipal (pemilik) dan agen (manajer) (Khan dkk., 2012). Aziz dkk. (2017) mengungkapkan bahwa untuk memastikan manajemen bertindak sesuai dengan kepentingan pemegang saham, maka tata kelola perusahaan dapat dianggap sebagai alat yang efektif untuk mengamati, mengendalikan, dan memeriksa tindakan manajemen, sehingga dalam kaitannya dengan agen yang merupakan manajer puncak dan prinsipal yang merupakan pemegang saham.

Teori Agensi juga dapat memprediksi pembentukan komite audit sebagai sarana untuk mengurangi biaya agensi, di mana para direktur independen dianggap sebagai pemantau yang lebih baik, sehingga pada pengawasan komite audit terhadap struktur pengendalian internal perusahaan menunjukkan bahwa semakin besar proporsi direktur non-eksekutif di komite audit, semakin kecil kemungkinan organisasi akan mengalami penyalahgunaan aset (Chapple dkk., 2009). 


\section{Teori Signaling}

Teori Signaling berguna untuk menggambarkan perilaku ketika dua pihak (individu atau organisasi) memiliki akses ke informasi yang berbeda, misalnya satu pihak menjadi pengirim sehingga harus memilih apakah dan bagaimana mengkomunikasikan (atau memberi sinyal) informasi itu, semnentara pada pihak lain yang berperan sebagai penerima harus memilih cara menafsirkan sinyal (Connelly dkk., 2011). Adanya asimetri informasi antara pihak manajemen (agen) dengan pihak prinsipal (pemegang saham) ini mengacu pada teori signaling (Aziz dkk., 2017).

\section{Pengembangan dan Perumusan Hipotesis}

\section{Ukuran Dewan Direksi dan Restatement}

Hasnan, Marzuki, dkk. (2017) dan Hasnan dan Marzuki (2017) menunjukkan bahwa adanya hubungan negatif dan signifikan antara ukuran dewan dengan financial restatement yang menunjukkan bahwa jumlah dapat memberikan sumberdaya tambahan pada pengetahuan dan pengalaman bisnis untuk memperbaiki kualitas dari pengawasan manajerial. Sehingga hipotesis pertama dalam penelitian adalah:

$\mathbf{H}_{1}=$ Ukuran dewan direksi berpengaruh negatif terhadap restatement .

\section{Proporsi Komisaris Independen dan Restatement}

Hubungan antara proporsi komisaris independen dengan restatement telah diteliti oleh Zhizhong dkk. (2011), Veronica dkk. (2005), dan Beasley (1996) memiliki pendapat yang sama terhadap proporsi komisaris independen memiliki hubungan negatif terhadap restatement. Proporsi komisaris independen memiliki pengaruh negatif dengan kemungkinan financial restatement, dan menunjukkan bahwa prediksi tersebut signifikan karena bukti menunjukkan bahwa komisaris independen dapat memperbaiki tata kelola dalam perusahaan dan dapat mengurangi kemungkinan oportunisme (Zhizhong dkk., 2011). Veronica dkk. (2005) juga memprediksi hal yang sama dengan Zhizhong dkk. (2011) yaitu proporsi komisaris independen memiliki hubungan negatif dengan kemungkinan restatement karena dewan independen lebih efektif dalam mecegah salah saji financial restatement. Proporsi komisaris independen lebih rendah untuk perusahaan yang mengalami kecurangan laporan keuangan dari pada perusahaan yang tidak melakukan kecurangan (Beasley, 1996). Sehingga hipotesis kedua penelitian adalah:

$\mathrm{H}_{2}=$ Proporsi komisaris independen berpengaruh terhadap restatement.

\section{Fekuensi Rapat Komite Audit dan Restatement}

Frekuensi rapat komite audit berhubungan negatif dengan kemungkinan terjadinya restatement. Frekuensi rapat pada penelitian Abbott dkk. (2004) berdasarkan pada laporan BRC (1999) yaitu frekuensi rapat komite audit minimal empat kali dalam setahun, hal ini menyiratkan bahwa komite audit harus melakukan rapat setiap tiga bulan sekali sehingga secara tidak langsung BRC menyarankan agar perusahaan memiliki laporan kuartalan, dan hasil dari penelitian menunjukkan bahwa frekuensi rapat komite 
audit yang dilakukan minimal empat kali dalam setahun berpengaruh negatif terhadap restatement (Abbott dkk., 2004). Sehingga hipotesis ketiga dalam penelitian, yaitu:

$\mathrm{H}_{3}=$ Frekuensi rapat komite audit berpengaruh negatif terhadap restatement .

\section{METODA PENELITIAN}

Pemilihan sample dengan kriteria purposive sampling, dengan mengambil data dari BEI periode 2012 sampai 2016 dengan mengeluarkan industri keuangan, mencari restatement dengan keyword "restatement", "restate", "restated", "penyajian kembali" atau "disajikan kembali", dan disesuaikan dengan kriteria (GAO, 2002), dan data yang tidak lengkap akan dikeluarkan dari sampel. Selanjutnya sampel perusahaan yang terpilih dipasangkan dengan perusahaan yang tidak melakukan restatement pada tahun yang sama, sektor industri yang sama, dan memiliki ukuran perusahaan yang hampir sama.

\section{Metode Pengumpulan Data}

Penelitian menggunakan model logit untuk mengukur kemungkinan perusahaan melakukan restatement dengan menggunakan variabe dependen pada periode yang sama. Penelitian menggunakan bantuan software pengelola data SPSS 20. Persamaan regresi logistik yang digunakan untuk menguji variabel dependen yang menggunakan data dummy dengan variabel independennya adalah:

$$
\text { Ln Restate }=\beta_{0}+\beta_{1} \mathrm{UDD}+\beta_{2} \mathrm{PKI}+\beta_{3} \mathrm{FRKA}+\varepsilon
$$

Dimana Restate adalah Restatement, $\beta$ adalah koefisien regresi, UDD adalah variabel ukuran dewan direksi, PKI adalah variabel proporsi komisaris indepnden, FRKA adalah variabel frekuensi rapat komite audit, dan $\varepsilon$ adalah standar error.

\section{HASIL DAN PEMBAHASAN}

\section{Statistik Deskriptif}

Tabel 1

Statistik Deskriptif

\begin{tabular}{|l|c|c|c|c|c|c|c|}
\hline Variabel & Mean & SD & Skewness & Kurtosis & $\begin{array}{c}\text { Mean } \\
(F R)\end{array}$ & $\begin{array}{c}\text { Mean } \\
\text { (non- } \\
\text { FR })\end{array}$ & t-value \\
\hline UDD & 4,97 & 1,97 & 0,72 & $-0,31$ & 4,82 & 5,13 & 0,69 \\
\hline PKI & 41,43 & 11,33 & 1,16 & 1,13 & 40,72 & 42,16 & 0,55 \\
\hline FRKA & 5,12 & 2,22 & 1,60 & 2,84 & 5,67 & 4,55 & $-2,27$ \\
\hline
\end{tabular}

Sumber : output SPSS, 2018 (diolah)

Variabel jumlah dewan direksi (UDD) memiliki rata-rata 4,97 dengan standar deviasi sebesar 1,97. Nilai skewness dan kurtosis masing-masing sebesar 0,72 dan -0,31 artinya UDD berdistribusi secara normal. Rata-rata UDD pada perusahaan yang melakukan financial restatement adalah 4,82, dan untuk perusahaan yang tidak melakukan financial 
restatement adalah 5,13. Analisis uji beda t-value adalah 0,69 sehingga rata-rata UDD pada perusahaan yang melakukan financial restatement dan tidak melakukan financial restatement tidak berbeda.

Variabel proporsi komisaris independen (PKI) memiliki rata-rata 41,43 dengan standar deviasi sebesar 11,33. Nilai skewness dan kurtosis masing-masing sebesar 1,16 dan 1,13 artinya PKI berdistribusi secara normal. Rata-rata PKI pada perusahaan yang melakukan financial restatement adalah 40,72, dan untuk perusahaan yang tidak melakukan financial restatement adalah 42,16. Analisis uji beda t-value adalah 0,55 sehingga rata-rata PKI pada perusahaan yang melakukan financial restatement dan tidak melakukan financial restatement tidak berbeda.

Variabel frekuensi rapat komite audit (FRKA) memiliki rata-rata 5,12 dengan standar deviasi sebesar 2,22. Nilai skewness dan kurtosis masing-masing sebesar 1,60 dan 2,84 artinya FRKA tidak berdistribusi secara normal. Rata-rata FRKA pada perusahaan yang melakukan financial restatement adalah 5,67, dan untuk perusahaan yang tidak melakukan financial restatement adalah 4,55. Analisis uji beda t-value adalah -2,727 sehingga rata-rata FRKA pada perusahaan yang melakukan financial restatement dan tidak melakukan financial restatement berbeda secara signifikan.

\section{Uji Korelasi}

Tabel 2

Pearson Correlation Matrik

\begin{tabular}{|l|c|c|c|c|}
\hline Variabel & UDD & PKI & FRKA & FR \\
\hline UDD & 1 & 0,16 & 0,07 & $-0,08$ \\
\hline PKI & & 1 & $-0,020$ & $-0,06$ \\
\hline FRKA & & & 1 & 0,25 \\
\hline FR & & & & 1 \\
\hline
\end{tabular}

Sumber : output SPSS, 2018 (diolah)

Uji korelasi menunjukkan bahwa UDD terhadap FR memiliki hubungan negatif tetapi tidak memiliki hubungan korelasi. Variabel PKI terhadap FR hubungan negatif tetapi memiliki hubungan korelasi yang kuat. Akhirnya, variabel FRKA terhadap FR memiliki hubungan positif dan signifikan memiliki hubungan, dengan tingkat derajat korelasi yang lemah. 


\section{Logistic Regression}

Logistic regression digunakan untuk menguji probabilitas terjadinya variabel terikat dapat diprediksi dengan variabel bebasnya (Ghozali, 2006). Hasil output hosmer and lemeshow test menunjukkan nilai chi-square 11,582 dengan signifikansi sebesar 0,115 yang berarti bahwa model penelitian layak digunakan untuk analisis selanjutnya. Hasil analisis logistic regression ditunjukkan Tabel 3.

\section{Tabel 3}

Logistic Regression

\begin{tabular}{|l|c|c|c|c|c|c|}
\hline \multicolumn{1}{|c|}{ Variabel } & B & S.E. & Wald & df & Sig. & $\operatorname{Exp(B)}$ \\
\hline UDD & $-0,104$ & 0,124 & 0,706 & 1 & 0,401 & 0,901 \\
\hline PKI & $-0,009$ & 0,022 & 0,167 & 1 & 0,683 & 0,991 \\
\hline FRKA & 0,277 & 0,132 & 4,440 & 1 & 0,035 & 1,320 \\
\hline
\end{tabular}

Sumber : output SPSS, 2018 (diolah)

Tabel 3 menunjukkan bahwa UDD memiliki koefisien regresi sebesar -0,104, artinya dengan banyaknya jumlah dewan direksi pada suatu perusahaan maka akan dapat mengurangi kemungkinan perusahaan melakukan financial restatement. Hasil penelitian untuk UDD terhadap financial restatement tidak signifikan $\left(\mathrm{H}_{1}\right.$ ditolak) karena jumlah dewan direksi dalam perusahaan memiliki skala tertentu artinya jumlah dewan direksi dalam perusahaan tergantung kebutuhan perusahaan. Hasil penelitian sesuai dengan Veronica dkk. (2005), Ma dkk. (2015), dan Cai dkk. (2014).

Variabel PKI memiliki koefisien regresi sebesar -0,009 yang berarti PKI memiliki hubungan negatif dengan financial restatement, sehingga dengan tingginya proporsi komisaris independen dalam perusahaan diharapkan dapat mengurangi kemungkinan perusahaan melakukan financial restatement. Hasil menunjukkan bahwa PKI tidak signifikan terhadap financial restatement $\left(\mathrm{H}_{2}\right.$ ditolak), hasil ini sesuai dengan Nahar Abdullah dkk. (2010), Ma dkk. (2015), Hasnan, Marzuki, dkk. (2017), Hasnan dan Marzuki (2017), dan Cai dkk. (2014).

Variabel terakhir yang diuji adalah FRKA yang memiliki hubungan positif dan signifikan. Hipotesis $\mathrm{H}_{3}$ ditolak, sehingga dengan sering dilakukannya pertemuan rapat komite audit tidak dapat menjamin perusahaan akan terhindar dari financial restatement. Hasil penelitian sesuai dengan Pertiwi (2017), Lin dkk. (2006), dan Rani dkk. (2011).

\section{SIMPULAN}

Hasil analisis data menunjukkan bahwa jumlah dewan direksi dan proporsi komisaris independen perusahaan memiliki hubungan negatif dengan terjadinya financial restatement, namun tidak signifikan. Hal ini disebabkan karena jumlah dewan direksi dan proporsi komisaris independen memiliki skala tertentu artinya jumlah dewan direksi dan proporsi komisaris independen harus menyesuaikan kebutuhan perusahaan. apabila jumlah dewan direksi dam komisaris independen terlalu banyak akan kurang efektif dalam menjalankan aktifitasnya, begitu pula sebaliknya dengan jumlah yang sedikit kinerja mereka akan kurang maksimal. Variabel frekuensi rapat komite audit memiliki 
hubungan yang positif dan signifikan, namun tidak sesuai dengan hipotesis penelitian. Hal ini mungkin dikarenakan frekuensi pertemuan komite audit yang terlalu sering sehingga menyebabkan aktivitas komite audit akan terganggu karena akan mengganggu efisiensi waktu dan independensi komite audit.

Penelitian tentang financial restatement di Indonesia relatif sedikit, sehingga dapat menjadi peluang bagi peneliti di masa depan untuk mengembangkan riset penelitian tentang financial restatement. Peneliti yang akan datang diharapkan dapat menambahkan variabel kontrol seperti kinerja keuangan perusahaan, menggunakan kriteria restatement yang berbeda, dan dapat menambahkan beberapa variabel independen lain yang sesuai.

\section{DAFTAR PUSTAKA}

Abbott, L. J., Parker, S., \& Peters, G. F. (2004). Audit committee characteristics and restatements. Auditing: A Journal of Practice \& Theory, 23(1), 69-87.

Agrawal, A., \& Chadha, S. (2005). Corporate governance and accounting scandals. The Journal of Law and Economics, 48(2), 371-406.

Aziz, N. F., Mohamed, M., Hasnan, S., Sulaiman, N., \& Aziz, R. A. (2017). Ownership Structure and Financial Restatement in Malaysia. Pertanika Journal of Social Science And Humanities, 25, 227-236.

Beasley, M. S. (1996). An empirical analysis of the relation between the board of director composition and financial statement fraud. Accounting review, 443-465.

Cai, J., \& Chang, Y. (2014). Research on the Relationship of Financial Restatement and Characteristics of the Board of Listed Real Estate Companies ICCREM 2014: Smart Construction and Management in the Context of New Technology (pp. 1072-1078).

Chapple, L. J., Ferguson, C., \& Kang, D. (2009). Corporate governance and misappropriation. Journal of Forensic and Investigative Accounting, 1(2), 1-26.

Connelly, B. L., Certo, S. T., Ireland, R. D., \& Reutzel, C. R. (2011). Signaling theory: A review and assessment. Journal of management, 37(1), 39-67.

GAO, O. (2002). Financial statement restatements: Trends, market impacts, regulatory responses, and remaining challenges. Report to the Chairman, Committee on Banking, Housing, and Urban Affairs, US Senate.

Ghozali, I. (2006). Aplikasi analisis multivariate dengan program SPSS: Badan Penerbit Universitas Diponegoro.

Hasnan, S., \& Marzuki, H. (2017). Board of Directors' Characteristics and Financial Restatement.

Hasnan, S., Marzuki, H., \& Shuhidan, S. M. (2017). Effects of Board Characteristics on Financial Restatement in Malaysia. PERTANIKA JOURNAL OF SOCIAL SCIENCE AND HUMANITIES, 25, 255-263. 
Khan, M. Y., \& D'Silva, K. E. (2012). Corporate Governance Quality and Earnings Management: Evidence from UK FTSE 100 and AIM (2007-10). Paper presented at the 10th Academic conference on Internal Auditing \& Corporate Governance, Verona University (Italy).

Lin, J. W., Li, J. F., \& Yang, J. S. (2006). The effect of audit committee performance on earnings quality. Managerial Auditing Journal, 21(9), 921-933.

Ma, Z., \& Chang, Y. (2015). Correlation Analysis of Board Characteristics and Financial Restatement in Real Estate Listed Companies ICCREM 2015 (pp. 977-986).

Nahar Abdullah, S., Zalina Mohamad Yusof, N., \& Naimi Mohamad Nor, M. (2010). Financial restatements and corporate governance among Malaysian listed companies. Managerial Auditing Journal, 25(6), 526-552.

Pertiwi, N. (2017). Hubungan Antara Performa Komite Audit dengan Earnings Quality. CALYPTRA, 1(1), 1-19.

Rani, P. M., \& Syafruddin, M. (2011). Pengaruh Kinerja Komite Audit terhadap Manajemen Laba (dengan Menggunakan Earning Restatement sebagai Proksi dari Manajemen Laba). Universitas Diponegoro.

Veronica, S., \& Bachtiar, Y. S. (2005). The Role of Corporate Governance in Preventing Misstated Financial Statement. Jurnal Akuntansi dan Keuangan Indonesia, 2(1), 159-173.

Yuristisia, C., \& Lukviarman, N. (2008). Analisis Hubungan antara Strong Boards dan External Governance terhadap Accounting Restatement. Jurnal Siasat Bisnis, 12(2).

Zhizhong, H., Juan, Z., Yanzhi, S., \& Wenli, X. (2011). Does corporate governance affect restatement of financial reporting? Evidence from China. Nankai Business Review International, 2(3), 289-302. 